\title{
Real-Time G-Protein-Coupled Receptor Imaging to Understand and Quantify Receptor Dynamics
}

\author{
María S. Aymerich, ${ }^{1,2} \mathrm{~J}$. López-Azcárate, ${ }^{1} \mathrm{~J}$. Bonaventura, ${ }^{3}$ \\ G. Navarro, ${ }^{3}$ D. Fernández-Suárez, ${ }^{1}$ V. Casadó, ${ }^{3}$ F. Mayor, ${ }^{4}$ C. Lluís, ${ }^{3}$ \\ M. Valencia, ${ }^{1}$ J. Artieda, ${ }^{1}$ and Rafael Franco ${ }^{1}$ \\ ${ }^{1}$ Área de Neurociencias, CIMA, Universidad de Navarra, \\ Avenida Pío XII 55, 31008 Pamplona, Spain \\ ${ }^{2}$ Departamento de Bioquímica y Biología Molecular, Unversidad de Navarra, \\ C/Irunlarrea s/n, 31008 Pamplona, Spain \\ ${ }^{3}$ Centro de Investigación Biomédica en Red sobre Enfermedades Neurodegenerativas \\ (CIBERNED) and Departamento de Bioquímica y Biología Molecular, \\ Facultad de Biología, Universidad de Barcelona, Avenida Diagonal 645, \\ 08028 Barcelona, Spain \\ ${ }^{4}$ Departamento de Biología Molecular and Centro de Biología Molecular \\ "Severo Ochoa", Consejo Superior de Investigaciones Científicas-Universidad \\ Autónoma de Madrid (CSIC-UAM), 28049 Madrid, Spain
}

Received 24 March 2011; Accepted 8 September 2011

Academic Editor: S. Ferré

Understanding the trafficking of G-protein-coupled receptors (GPCRs) and their regulation by agonists and antagonists is fundamental to develop more effective drugs. Optical methods using fluorescent-tagged receptors and spinning disk confocal microscopy are useful tools to investigate membrane receptor dynamics in living cells. The aim of this study was to develop a method to characterize receptor dynamics using this system which offers the advantage of very fast image acquisition with minimal cell perturbation. However, in short-term assays photobleaching was still a problem. Thus, we developed a procedure to perform a photobleaching-corrected image analysis. A study of short-term dynamics of the long isoform of the dopamine type 2 receptor revealed an agonist-induced increase in the mobile fraction of receptors with a rate of movement of $0.08 \mu \mathrm{m} / \mathrm{s}$ For long-term assays, the ratio between the relative fluorescence intensity at the cell surface versus that in the intracellular compartment indicated that receptor internalization only occurred in cells co-expressing $\mathrm{G}$ protein-coupled receptor kinase 2 . These results indicate that the lateral movement of receptors and receptor internalization are not directly coupled. Thus, we believe that live imaging of GPCRs using spinning disk confocal image analysis constitutes a powerful tool to study of receptor dynamics.

KEYWORDS: dopamine receptor, trafficking, internalization, live cell imaging 


\section{INTRODUCTION}

G-protein-coupled receptors (GPCRs) are key academic and industrial targets for the development of drugs, agonists, and antagonists, and indeed, they are targeted by about $50 \%$ of the currently available drugs. Knowledge of plasma membrane dynamics and receptor trafficking is crucial to understand how GPCRs function and mediate signal transduction. The study of receptor dynamics has advanced significantly by using fluorescent-tagged proteins in combination with fluorescence microscopy. Indeed, the recent development of spinning disk confocal systems provides a high resolution with low levels of illumination, preventing fluorophore damage and cytotoxicity when assaying live cells [1]. Thus, real-time, direct-view confocal microscopy offers the opportunity to observe and record fluorescent-tagged proteins with minimal cell perturbation [2].

Dopaminergic neurotransmission is mediated by dopamine receptors, and it is involved in key neural activities controlling locomotion, addiction, cognition, learning, and memory formation [3]. Indeed, the deregulation of dopamine signaling is a fundamental element in the clinical symptoms of Parkinson's disease and schizophrenia, and agonists and antagonists of dopamine receptors are currently used to treat the symptoms of these diseases $[4,5]$. One way to modulate synaptic strength is to regulate the number of receptors at specific locations in neurons [6]. The number of receptors in membrane domains depends on their insertion, lateral diffusion, and endocytosis. Current optical methods to investigate cell surface receptor dynamics, such as fluorescence recovery after photobleaching (FRAP), involve single-point scanning confocal systems and they are hampered by the rapid photobleaching effects or phototoxicity [7].

The aim of the present study was to develop a method to characterize receptor membrane dynamics using a spinning disk confocal microscopy and the long isoform of the dopamine type 2 receptor $\left(D_{2 L} R\right)$ as a model. To explore receptor dynamics, HEK-293 cells were transfected with $\mathrm{D}_{2 \mathrm{~L}} \mathrm{R}$ fused to yellow fluorescent protein (YFP), and fluorescence was monitored at different times after exposure to the $\mathrm{D}_{2 \mathrm{~L}} \mathrm{R}$ agonist, quinpirole. As the effect of photobleaching is not completely abolished with the spinning disk system $[2,8]$, the first aim of the study was to characterize and correct this effect. Corrected images were then used to analyze receptor mobility in the plasma membrane, before an image-based approach was developed to measure receptor internalization. The strategy described here represents a powerful tool for the realtime analysis of receptor dynamics in minimally perturbed living cells.

\section{MATERIALS AND METHODS}

\subsection{Fusion Protein and Expression Vector}

The human cDNA for $\mathrm{D}_{2 \mathrm{~L}} \mathrm{R}$ was cloned into pcDNA3.1 and was amplified without its stop codon using sense and antisense primers harboring unique EcoRI and KpnI sites. The amplified fragment was subcloned to be in frame into restriction sites of pEYFP-N1 (enhanced yellow variant of GFP; Clontech, Mountain View, CA) vector resulting in the plasmid $\mathrm{D}_{2 \mathrm{~L}} \mathrm{R}$-YFP. Expression of the construct was tested by confocal microscopy (see results) and the receptor functionality by agonist-induced cAMP determination and ERK1/2 phosphorylation levels [9]. Data in Figure 1 indicates that the YFP does not significantly affect the functionality of $\mathrm{D}_{2 \mathrm{~L}} \mathrm{R}$ in HEK-293 cells. The cDNA encoding GRK2 has been previously described [10].

\subsection{Cell Culture}

HEK-293 cells were grown in Dulbecco's modified Eagle's medium with GlutaMax (Gibco, Paisley, UK) supplemented with $100 \mathrm{U} / \mathrm{mL}$ penicillin/streptomycin (Gibco) and 5\% (v/v) of heat inactivated fetal bovine serum (Gibco). Cells were maintained at $37^{\circ} \mathrm{C}$ in an atmosphere of $5 \% \mathrm{CO}_{2}$ and were passaged when they were $80-90 \%$ confluent, twice a week. 


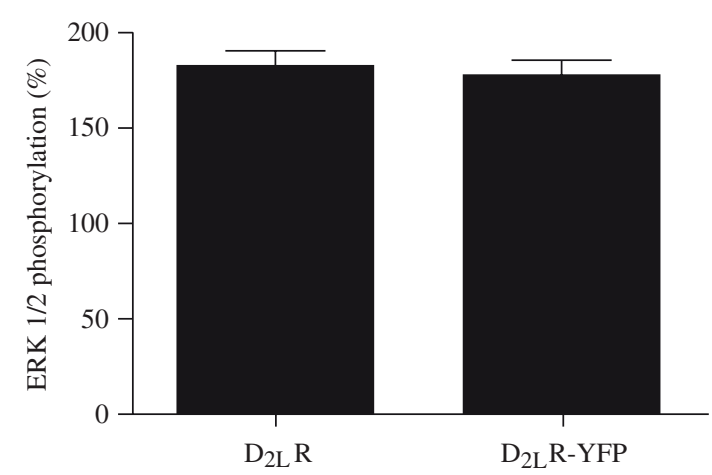

(a)

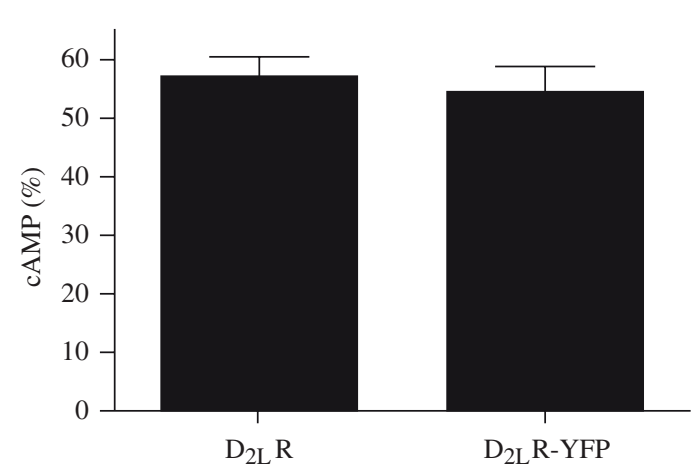

(b)

FIGURE 1: Characterization of the $D_{2 L}$ R-YFP fusion protein. HEK-293T cells were transiently transfected with $1 \mu \mathrm{g}$ of cDNA corresponding to $\mathrm{D}_{2 \mathrm{~L}} \mathrm{R}$ or $\mathrm{D}_{2 \mathrm{~L}} \mathrm{R}$-YFP and used $48 \mathrm{~h}$ posttransfection. (a) ERK1/2 phosphorylation levels in cells treated with $100 \mathrm{nM}$ quinpirole for $5 \mathrm{~min}$ (\% with respect to vehicle treated cells). (b) cAMP levels in cells stimulated with $3 \mu \mathrm{M}$ forskolin in the absence or in the presence of $100 \mathrm{nM}$ quinpirole (\% with respect to forskoline treatment). In (a) and (b), values correspond to the mean \pm SEM of three experiments performed in duplicates.

\subsection{Immunocytochemistry}

HEK-293T cells were grown on glass coverslips and were transiently transfected with $0.5 \mu \mathrm{g}$ of cDNA corresponding to $\mathrm{D}_{2 \mathrm{~L}} \mathrm{R}$-YFP or with $0.5 \mu \mathrm{g}$ of cDNA corresponding to YFP. After $48 \mathrm{~h}$ of transfection, cells were treated for 6 or $180 \mathrm{~min}$ with medium, $100 \mathrm{nM}$ quinpirole or $50 \mathrm{nM}$ dopamine. Cells were fixed in $4 \%$ paraformaldehyde for $15 \mathrm{~min}$ and washed with phosphate-buffered saline (PBS) containing $20 \mathrm{mM}$ glycine to quench the aldehyde groups. After permeabilization with PBS containing $0.05 \%$ Triton X-100 for $5 \mathrm{~min}$, cells were incubated $1 \mathrm{~h}$ at room temperature with PBS containing $1 \%$ bovine serum albumin and were labelled with the following primary antibodies: mouse monoclonal anti-GM130 antibody (1/250, BD Biosciences, Franklin Lakes, NJ, USA), mouse monoclonal antitransferrin receptor antibody (1/200, Invitrogen, Camarillo, CA, USA), or mouse monoclonal anti-LAMP1 antibody (1/200, Enzo, Farmingdale, NY, USA) for $1 \mathrm{~h}$, washed, and stained with the secondary Cy3 donkey anti-mouse antibody (1/200, Jackson Immunoresearch Laboratories, Baltimore, PA, USA) plus Hoescht as nuclei marker. $\mathrm{D}_{2 \mathrm{~L}} \mathrm{R}$-YFP was detected by monitoring fluorescence emission at $530 \mathrm{~nm}$. The slices were mounted using the mounting medium and were observed in a Leica SP2 confocal microscope. Images were acquired in a sequential mode using a 63x Plan Apochromat NA 1.4 oil objective and the appropriate filter combination.

\subsection{ERK 1/2 Phosphorylation Assays}

HEK-293T cells, transiently transfected with $1 \mu \mathrm{g}$ of cDNA corresponding to $\mathrm{D}_{2 \mathrm{~L}} \mathrm{R}$ or $\mathrm{D}_{2 \mathrm{~L}} \mathrm{R}-\mathrm{YFP}$, were cultured in serum-free medium for $16 \mathrm{~h}$ before the addition of $100 \mathrm{nM}$ quinpirole for $5 \mathrm{~min}$. Cells were lysed in ice-cold lysis buffer (50 mM Tris- $\mathrm{HCl} \mathrm{pH}$ 7.4, $50 \mathrm{mM} \mathrm{NaF}, 150 \mathrm{mM} \mathrm{NaCl}, 45 \mathrm{mM} \beta$-glycerophosphate, $1 \%$ Triton $\mathrm{X}-100,20 \mu \mathrm{M}$ phenyl-arsine oxide, $0.4 \mathrm{mM} \mathrm{NaVO}_{4}$ and protease inhibitor cocktail), and ERK $1 / 2$ phosphorylation was determined as indicated elsewhere $[11,12]$.

\section{5. cAMP Determination}

HEK-293T cells, transiently transfected with $1 \mu \mathrm{g}$ of cDNA corresponding to $\mathrm{D}_{2 \mathrm{~L}} \mathrm{R}$ or $\mathrm{D}_{2 \mathrm{~L}} \mathrm{R}$-YFP, were grown in $25 \mathrm{~cm}^{2}$ flasks to $80 \%$ confluence and incubated in serum-free medium for $16 \mathrm{~h}$ before the experiment. On the day of experiment, the cells were preincubated with $50 \mu \mathrm{M}$ zardaverine (Tocris, Ellisville, MO, 
USA) as phosphodiesterase inhibitor for $10 \mathrm{~min}$ at $37^{\circ} \mathrm{C}$ and treated for $10 \mathrm{~min}$ with $100 \mathrm{nM}$ quinpirole in the presence or the absence of $3 \mu \mathrm{M}$ forskolin (Sigma, St. Louis, MO, USA). To stop the reaction, cells were placed on ice and washed with ice-cold phosphate-buffered saline. The cells were incubated with $200 \mu \mathrm{L}$ of $\mathrm{HClO}_{4}(4 \%)$ for $30 \mathrm{~min}$, and $1.5 \mathrm{M} \mathrm{KOH}$ was added to reach neutral $\mathrm{pH}$, and samples were centrifuged. The supernatant was frozen at $-20^{\circ} \mathrm{C}$. The accumulation of cAMP was measured with Cyclic AMP $\left({ }^{3} \mathrm{H}\right)$ Assay System (Amersham Biosciences, Uppsala, Sweden) as described in the manual from the manufacturer.

\subsection{Confocal Microscopy}

The 8 well $\mu$-slides (Ibidi, Munich, Germany) were coated with collagen, $40 \mu \mathrm{g} / \mathrm{cm}^{2}$ (Becton Dickinson, Bedford, MA), and poly-D-lysine, $20 \mu \mathrm{g} / \mathrm{cm}^{2}$ for $60 \mathrm{~min}$. Then, the coating solution was aspirated and washed with sterile phosphate buffered saline $(\mathrm{PBS})$. HEK-293 were seeded $\left(1 \times 10^{5}\right.$ cells per well $)$ and transfected $24 \mathrm{~h}$ later when they reached an $80-90 \%$ confluence. Cells were transiently transfected with $0.5 \mu \mathrm{g}$ of plasmid $\mathrm{D}_{2 \mathrm{~L}} \mathrm{R}-$ YFP using Lipofectamine 2000 (Invitrogen, Carlsbad, CA) according to manufacturer's protocol. Forty-eight hours after transfection, cells were analyzed using the confocal microscope.

The expression of $\mathrm{D}_{2 \mathrm{~L}} \mathrm{R}$-YFP was directly visualized under the spinning disk confocal module, Ultraview ERS (Perkin Elmer, Waltham, MA), assemble to an inverted microscope (Zeiss Axiovert 200, Gottingen, Germany). Data were collected with an electron multiplier CCD digital camera C9100-50 (Hamamatsu, Herrsching, Germany). Around 90\% of transfected cells expressed the protein in the cell surface. All parameters of the microscope were kept identical in the different experiments performed. From each assay, a stack of images was obtained at every time point using water immersion $63 \mathrm{x}$ or dry 40x objectives. For short-term experiments, data from a stack of $6 \mu \mathrm{m}$ with a slide spacing of $1 \mu \mathrm{m}$ were recorded every $1 \mathrm{~s}$ along a total time of 6 minutes. For long-term experiments, a larger stack with a slice spacing of $0.5 \mu \mathrm{m}$ was obtained every $30 \mathrm{~s}$ along 3 hours. Recordings were performed in samples kept in a culture chamber at $37^{\circ} \mathrm{C}$ and $5 \% \mathrm{CO}_{2}$ in culture medium. For further analysis, individual images, both from every plane of the stack and from the whole stack, were transformed into a movie format using the Ultraview ERS software.

\subsection{Image Analysis}

A total of 361 images (frames) were analyzed in each experiment using MATLAB 7.7 software (The MathWorks, Natick, MA). Image size was $976 \times 816$ pixels (width and height, resp.).

\subsubsection{Plasma Membrane Analysis}

The fluorescence intensity on the plasma membrane was analyzed in one plane from the stack in a semiautomatic way. First, the effect of cell movement across time in single planes was minimized by means of normalized two-dimensional cross-correlation. Consecutive frames were aligned against displacements in the $X$ or $Y$ axes so that realigned images showed the highest value of correlation. Next, a number of pixels were manually selected and spatially interpolated (cubic spline interpolation) to build a preliminary approximation of the cell's contour in the first frame of the movie. Then, the plasma membrane location was defined by the local maxima of the fluorescence intensity along this contour, which was detected and interpolated to obtain a cubic spline interpolation of the fluorescence intensity. In all frames, fluorescence intensity at each point of the cell surface was defined as the average fluorescence intensity in a 5-by-5 neighborhood of pixels around the selected points. All the process was carried out in a semiautomatic way until completing the 361 frames of the movie. The process was periodically interrupted to check and eventually correct the set of pixels that define the cell membrane contour. Due to repetitive laser exposition, and despite of the spinning disk, a certain degree of photobleaching was observed. Fluorescence intensity decay was modeled 
according to a multiexponential function, that could be accurately approximated by reducing the model to two exponential functions:

$$
F(t)=A \cdot e^{-C \cdot t}+B \cdot e^{-D \cdot t},
$$

where $A, B, C$, and $D$ are coefficients of the equation and $t$ is time, measured in seconds (time $0 \mathrm{~s}=$ frame 1 ). The pixel by pixel fluorescence decay along the plasma membrane could be modeled by the biexponential function parameters in each experiment and the temporal evolution of the fluorescence intensity could be efficiently represented as a $2 \mathrm{D}$ image. The $Y$ axis represents the perimeter of the plasma membrane (in pixels, 1 pixel $=0.13 \mu \mathrm{m}$ ), the $X$ axis shows the time (in seconds), and the color scale gives the corrected values of fluorescence intensity.

\subsubsection{Internalization}

To determine receptor internalization, a stack of images was used for analysis. A set of pixels along a line manually selected to cross the cell were studied. In the successive frames, the correct placement of the line of pixels was semiautomatically controlled and reselected when necessary. Fluorescence intensity values over the line of pixels showed two maxima corresponding to values at the plasma membrane and one minimum corresponding to the intensity along the nucleus. The ratio between values of each maximum versus the minimum was calculated for every time frame. The temporal evolution of this ratio was considered as a measure of internalization (internalization index).

\subsubsection{Tracking of $D_{2 L} R$-YFP-Containing Vesicles}

To follow traffic of vesicles containing $\mathrm{D}_{2 \mathrm{~L}} \mathrm{R}$-YFP, a stack of images was used. Realignment of consecutive frames was done by using a two-dimensional correlation coefficient, as described above. $\mathrm{D}_{2 \mathrm{~L}} \mathrm{R}-\mathrm{YFP}$-containing vesicles were manually selected on the first frame (or in the frame where they became clearly visible) and were automatically tracked along time. Both $X$ and $Y$ coordinates were measured in each frame for every single vesicle and, using these values, the Euclidean distance covered by each vesicle was computed in successive frames.

\subsection{Statistics}

Statistical analyses were performed using SPSS 15.0 for Windows (SPSS Inc., Chicago, IL, USA).

\subsubsection{Cell Surface Trafficking}

Photobleaching-corrected 2D representations were analyzed using the first 30 frames $(30 \mathrm{~s})$ of each experiment as reference period. Normalized fluorescence intensity of each pixel along time, related to the reference period, was computed according to the following equation:

$$
\mathrm{N} F \mathrm{I}_{i j}=\frac{F \mathrm{I}_{i j}-\mathrm{m} F_{i}}{\operatorname{std} F_{i}}
$$

$F \mathrm{I}_{i j}$ stands for fluorescence of the $i$ th pixel in the $j$ th frame, and $\mathrm{m} F_{i}$ and $\operatorname{std} F_{i}$ are the mean and standard deviations of the fluorescence intensity for the pixel $i$ in the reference period, respectively. These values represent the fluorescence intensity deviation of every pixel, at every time, related to an $N(0,1)$ distribution. Thus, absolute values of the normalized fluorescence intensity greater than 1.96 imply significant variations 
in the fluorescence intensity with respect to the reference period. The mean and the variance of the normalized fluorescence intensity (along the plasma membrane contour) were calculated at every time point (averaging the values in a 5 frame/second sliding window). The variance value gave a temporal evolution of fluorescence intensity variations, whereas the mean value offered a measure of the net increase/decrease in the fluorescence intensity. A repeated measures one-way ANOVA was used to assess the statistical differences between control and treated group cells, considering time course. This analysis was followed by nonpaired $t$-test as post hoc test. On the same 2D representations, receptor speed was measured. After quinpirole addition, fluorescence clusters were manually selected and automatically tracked to study the timecourse of their position variation. The mean speed was then obtained computing the cumulative distance covered by every fluorescence cluster and dividing it by the time used to cover it. The mean speed and its respective standard deviation were computed for the different cells analyzed. The mobile fraction was computed as the percentage of pixels displaying, at $180 \mathrm{~s}$, a significant variation in the normalized fluorescence intensity.

\subsubsection{Internalization}

In order to compare the internalization index among the different assays, the measures obtained were normalized at each time point by the value measured at time 0 . Then, a repeated measure one-way ANOVA was used to search for significant differences between the different assays. Nonpaired $t$-test was used as post hoc test.

\subsubsection{Vesicular Trafficking}

Distance covered by each $\mathrm{D}_{2 \mathrm{~L}} \mathrm{R}$-YFP-containing vesicle was averaged using a 5 frames $(5 \mathrm{~s})$ sliding window in order to compare control versus treated group. A repeated measures one-way ANOVA was calculated to evaluate the statistical significance at every time point, using nonpaired $t$-test as post hoc test.

\section{RESULTS}

\subsection{Measurement of Plasma Membrane Fluorescence}

$\mathrm{D}_{2 \mathrm{~L}} \mathrm{R}$-YFP expression was visualized directly in living cells using a spinning disk confocal microscope. An image stack from transfected cells was taken at $63 \mathrm{x}$ magnification and the location of $\mathrm{D}_{2 \mathrm{~L}} \mathrm{R}-\mathrm{YFP}$ analyzed pixel-by-pixel. One plane from the stack corresponding to the medial portion of each cell was selected for analysis (Figure 2(a)). The plasma membrane contour was selected (Figure 2(b)), and the intensity of the fluorescence produced by $\mathrm{D}_{2 \mathrm{~L}} \mathrm{R}-\mathrm{YFP}$ (Figure 2(c)) was measured in the marked area. Measurement of fluorescence intensity along the membrane contour (see Section 2.7.1) is shown in Figure 2(d). Membrane fluorescence was determined at regular time intervals (360 determinations over 6 min, Figure 3(a)), and the decay in fluorescence intensity due to repetitive laser exposure was corrected for as described in Section 2.7.1. The stronger the initial fluorescence intensity was the faster the fluorescence decayed, when compared with pixels with lower initial fluorescence intensity. As photobleaching depended on the initial fluorescence intensity, a biexponential function was computed for all the pixels in the plasma membrane (Figure 3(b)). An example of the temporal evolution of fluorescence intensity from a single pixel with photobleaching, its biexponential fit, and the corrected values can be seen in Figure 3(c). Significantly, the parameters resulting from the data fitting (equation coefficients in Section 2.7.1) were similar in untreated cells and those treated with the dopamine receptor agonist, quinpirole (Mann-Whitney $U$-test, $P>0.05$ ), as evident in the graph showing the uncorrected and corrected fluorescence at different time points in Figure 3(d). Overall, these results demonstrate the robustness of the procedure used to correct for fluorescence decay. 


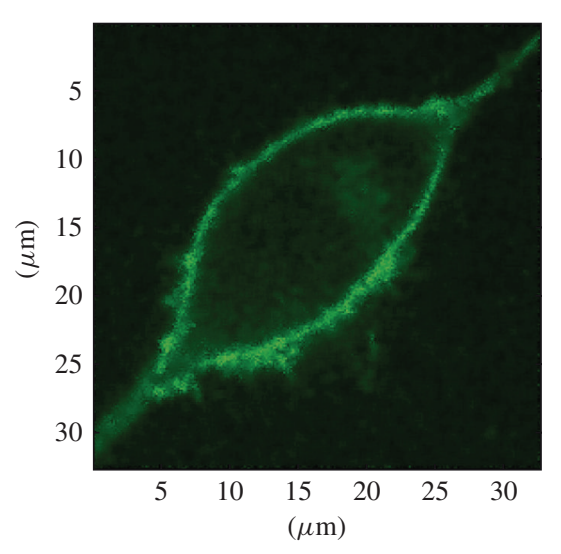

(a)

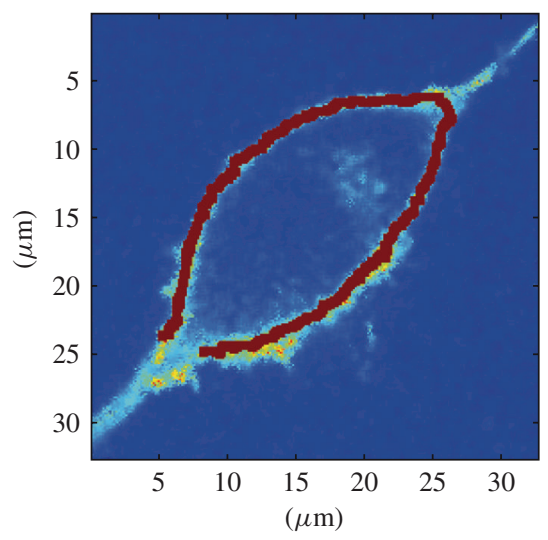

(c)

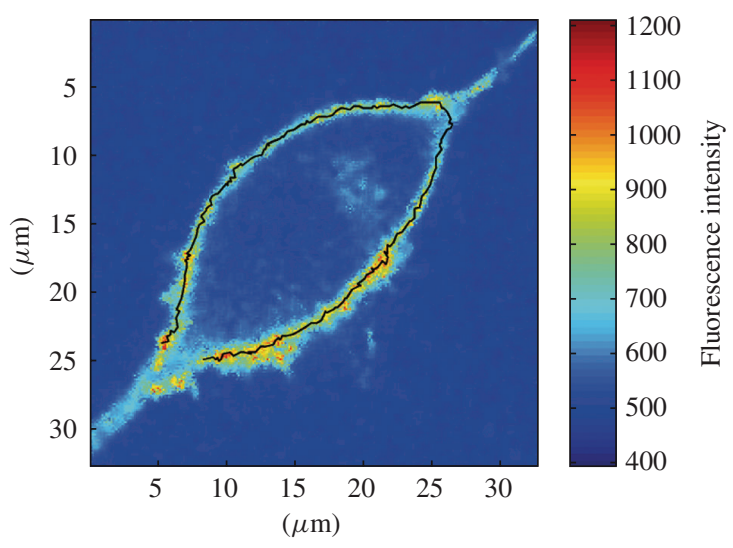

(b)

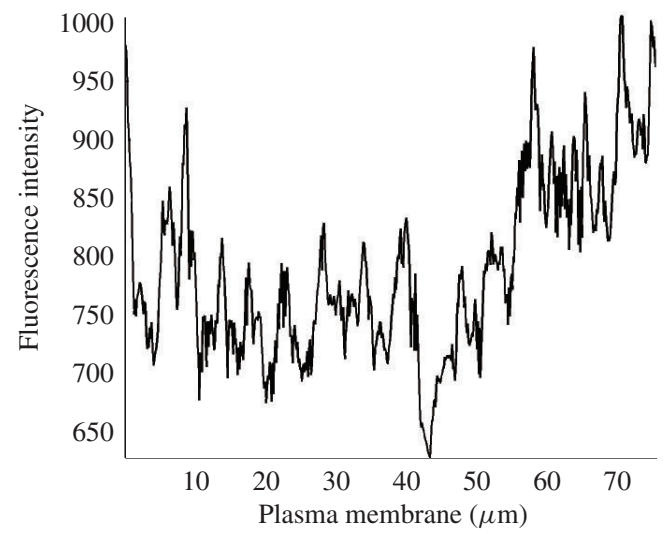

(d)

FIGURE 2: Measurement of fluorescent intensity in the plasma membrane at a single time point. (a) $A$ stack of images from $D_{2 L} R$-YFP-expressing cells was captured, and one plane was selected for analysis (see Section 2.7.1). (b) One-pixel-width line traced along the plasma membrane over the points with the highest fluorescence intensity. (c) Resulting mean fluorescence intensity in a $5 \times 5$ pixel area around each of the data points in (b). (d) Linear representation of the measure of the mean fluorescence intensity from the plasma membrane detected contour.

\section{2. $D_{2 L} R$ Surface Imaging}

Cell surface dynamics of $\mathrm{D}_{2 \mathrm{~L}} \mathrm{R}-\mathrm{YFP}$ provoked by agonist addition were studied using the methods described above. Quinpirole (or the vehicle alone in control samples) was added $30 \mathrm{~s}$ after beginning the recording and thus, the first $30 \mathrm{~s}$ of the experiment could be used as a reference for normalization purposes. Fluorescence decay at the plasma membrane of control and quinpirole-treated cells (Figures 4(a) and 4(d)) was corrected according to the biexponential model (Figures 4(b) and 4(e)), and the time-course of the quantitative changes in corrected fluorescence intensity was evaluated at each membrane location (Figures 4(c) and 4(f)). Both increases (red points) and decreases (blue points) in fluorescence intensity were detected in cells treated with quinpirole (Figure 4(f)). The fluorescence intensity of each pixel was normalized at each time point using the data obtained prior to the addition of the agonist (first $30 \mathrm{~s}$, Figure $4(\mathrm{~g})$ ). No changes in cumulative fluorescence intensity were detected along the plasma membrane over time in either control cells or those exposed to quinpirole (Figure 4(h), $P<0.05$, see Section 2.8.1) indicating that the net amount of $\mathrm{D}_{2 \mathrm{~L}} \mathrm{R}-$ YFP at the cell surface remained constant. Changes in fluorescence intensity are likely to occur due to the lateral movement of the receptors within the plasma membrane. The pixels corresponding to $\mathrm{D}_{2 \mathrm{~L}} \mathrm{R}$-YFP 


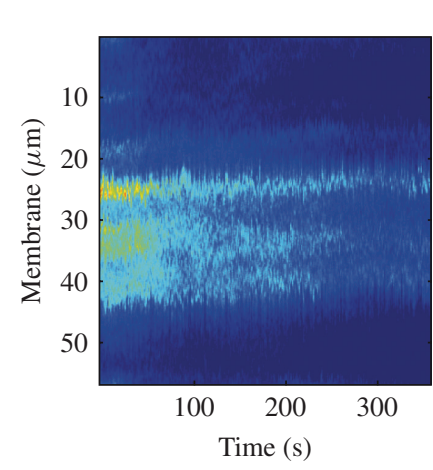

(a)

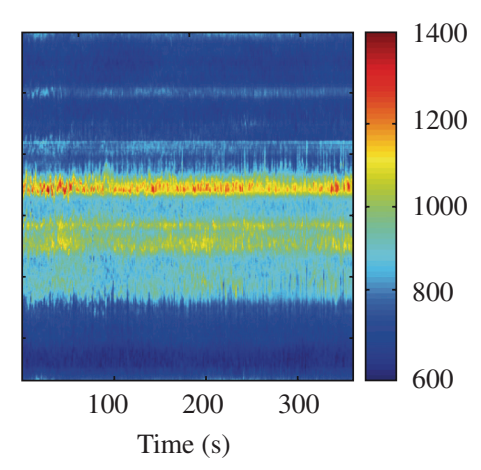

(b)

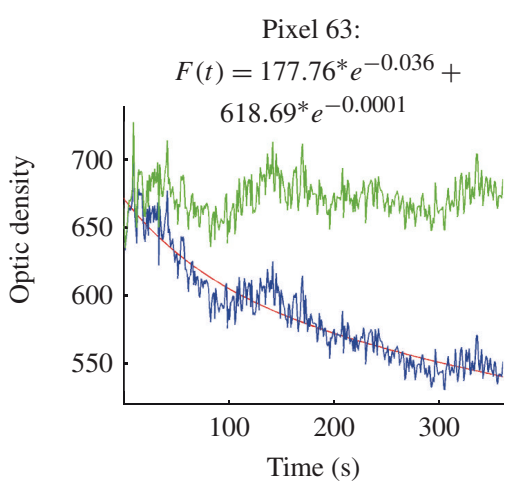

(c)
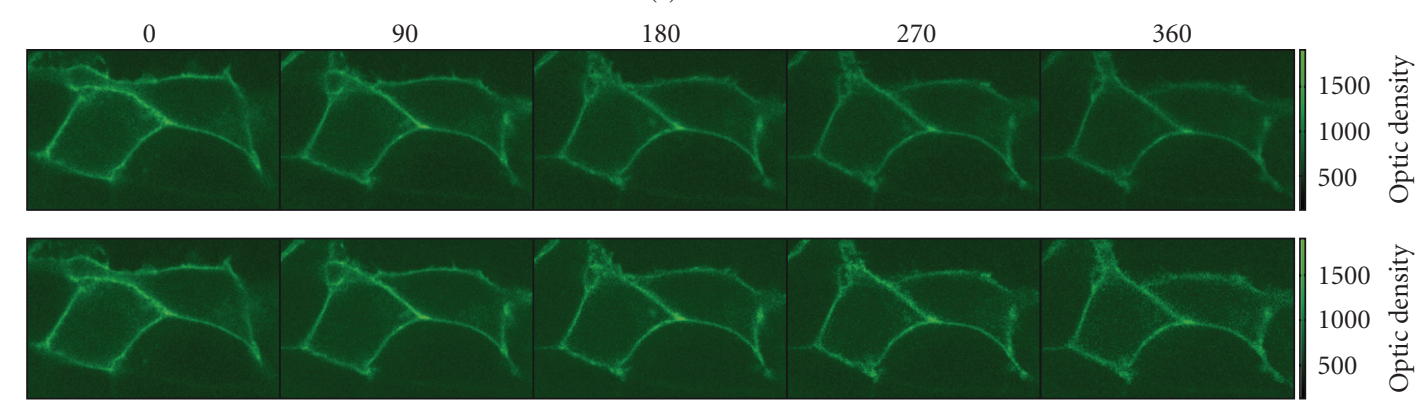

(d)

FIGURE 3: Photobleaching correction. $D_{2 L}$ R-YFP-transfected HEK-293 cells were recorded every second along $6 \mathrm{~min}$. One plane from the stack was selected for analysis and fluorescence intensity on the plasma membrane was measured at each time point. (a) The effect of fluorescence intensity fading on the plasma membrane was clearly visible due to repetitive laser exposition. (b) Photobleaching effect was corrected in each frame for each pixel using a biexponential equation. (c) The temporal evolution of fluorescence intensity of a single pixel (blue) followed the biexponential decay (red). The indicated biexponential equation (see Section 2.7.1) was used to correct the intensity value of this pixel along time (green). (d) Graphical results of the analysis showing images prior (upper row) and after correction (lower row); note that the fading is only visible in the upper row.

moved at a rate of $0.086 \pm 0.004 \mu \mathrm{m} / \mathrm{s}$ in the presence of the agonist and at $0.080 \pm 0.006 \mu \mathrm{m} / \mathrm{s}$ in the presence of vehicle alone. The receptor mobile fraction measured $180 \mathrm{~s}$ after treatment was $14 \pm 3 \%$ and $6 \pm 2 \%$ in the cells exposed to quinpirole and the control cells, respectively. Taken together, these results indicate that agonist treatment increased the receptor mobile fraction but that it had no effect on the rate of receptor movement (Figure 4(i)).

Using live imaging, we also studied the vesicular trafficking of $\mathrm{D}_{2 \mathrm{~L}} \mathrm{R}-\mathrm{YFP}$ expressed in HEK-293 cells by analyzing intracellular $\mathrm{D}_{2 \mathrm{~L}} \mathrm{R}$-YFP movement in images from a stack of planes. The fluorescence signal was assessed in a $4 \mu \mathrm{m}$ wide stack of images in which intracellular $\mathrm{D}_{2 \mathrm{~L}} \mathrm{R}-\mathrm{YFP}$-containing vesicles were observed (Figures 5(a) and 5(d)) for images from two different cells. The vesicles were selected and tracked throughout the experiment (1-3 vesicles per cell tracked over $360 \mathrm{~s}$ ), and the coordinates of each vesicle were noted in the first frame and compared with the new coordinates of each vesicle as the experiment proceeded (Figures 5(b) and 5(e)). The distance covered by each $\mathrm{D}_{2 \mathrm{~L}} \mathrm{R}$-YFP vesicle could be then calculated by deconvolution of the vesicle coordinates (Figures 5(c) and 5(f)). The mean distance covered by vesicles in cells exposed to quinpirole was $95 \pm 3 \mu \mathrm{m}(n=17)$, similar to that of and $98 \pm$ $4 \mu \mathrm{m}(n=23)$ in control cells (Figure 5(g)). One-way ANOVA revealed no significant differences in the distance covered by vesicles in each group, indicating that the agonist did not significantly affect short-term intracellular (6 min) traffic of $\mathrm{D}_{2 \mathrm{~L}} \mathrm{R}$-YFP-containing vesicles. 


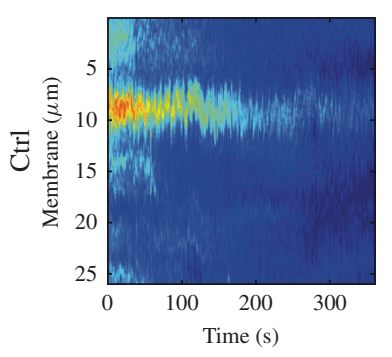

(a)

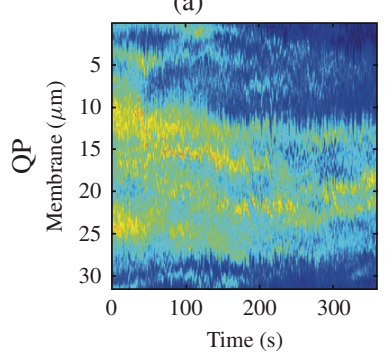

(d)

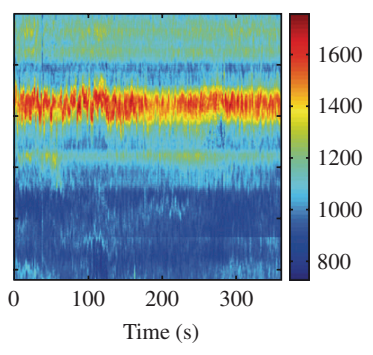

(b)

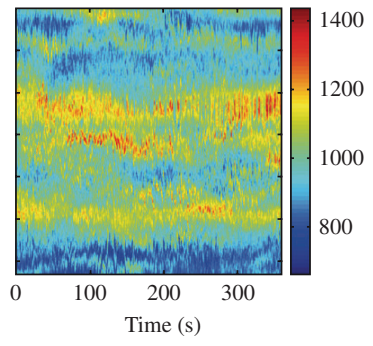

(e)

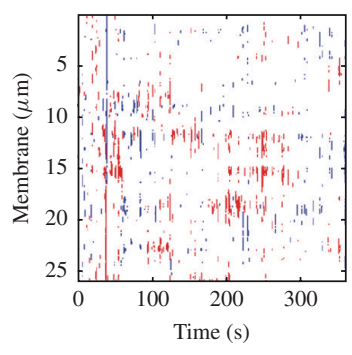

(c)

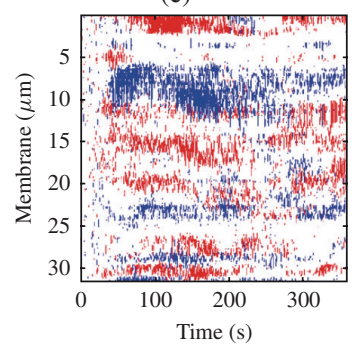

(f)
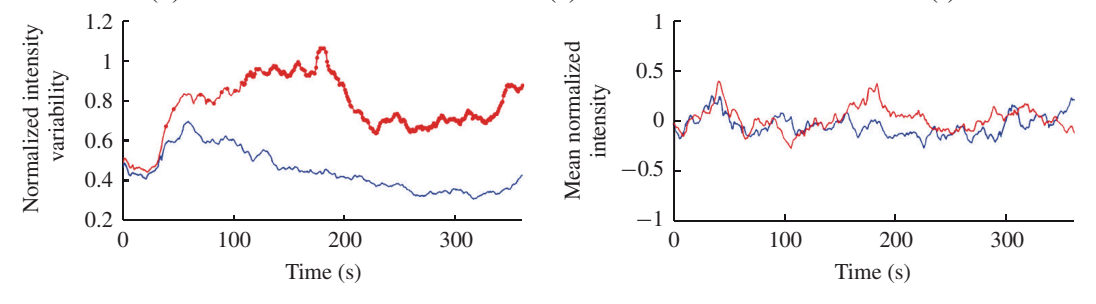
Ctrl
QP

$\cdot P<0.05$

(g)

(h)

(s)
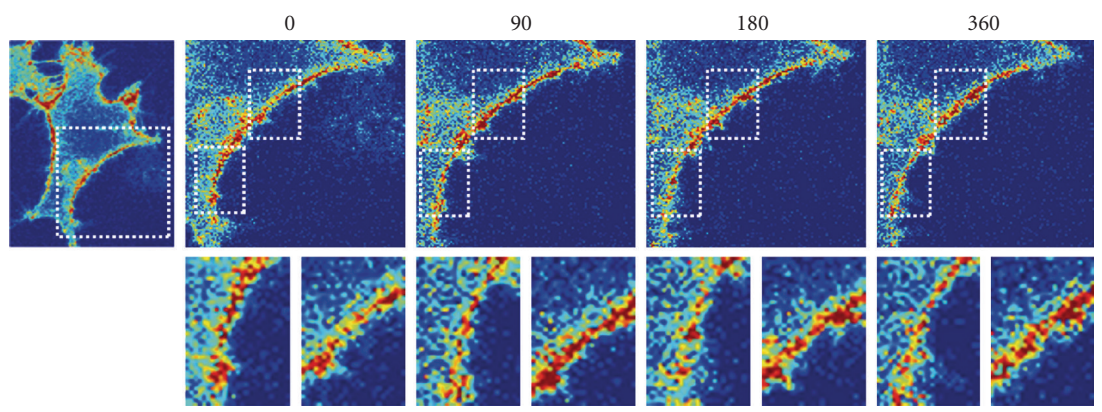

(i)
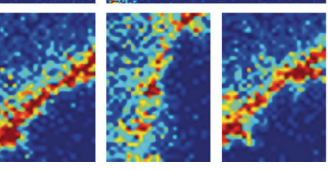

FIGURE 4: Short-term effect of quinpirole addition on $D_{2 L} R$-YFP expression in the plasma membrane. Distribution of $D_{2 L} R$-YFP on the plasma membrane in one single plane of transfected HEK-293 cells was studied over a period of time of $6 \mathrm{~min}$. Medium or $100 \mathrm{nM}$ quinpirole were added $30 \mathrm{~s}$ after the beginning of the recording. Plasma membrane fluorescence intensity measured in a medium- and a quinpirole-treated cell without photobleaching correction. Images of the same cells after photobleaching correction (b and e). Statistical significance plot $(P<0.05)$ of the fluorescence intensity of each pixel from medium- (c) and quinpirole-treated cells (f) normalized with respect to data obtained prior addition of medium or quinpirole (first $30 \mathrm{~s}$ ). Significant increases and decreases in fluorescence intensity are represented in red and blue, respectively. Data of the normalized fluorescence intensity $(\mathrm{g})$ for all analyzed cells (medium $n=22$, quinpirole $n=24$ ) showed significant changes only in agonist-treated cells and not before $70 \mathrm{~s}$ after agonist addition. (h) Temporal evolution of the mean value of the normalized fluorescence intensity. Oscillation around 0 indicates a lack of net increase or decrease in $D_{2 L}$ R-YFP surface expression. (i) Photobleachingcorrected plasma membrane magnification at different time points shows regions with evident increases and/or decreases in fluorescence intensity. 

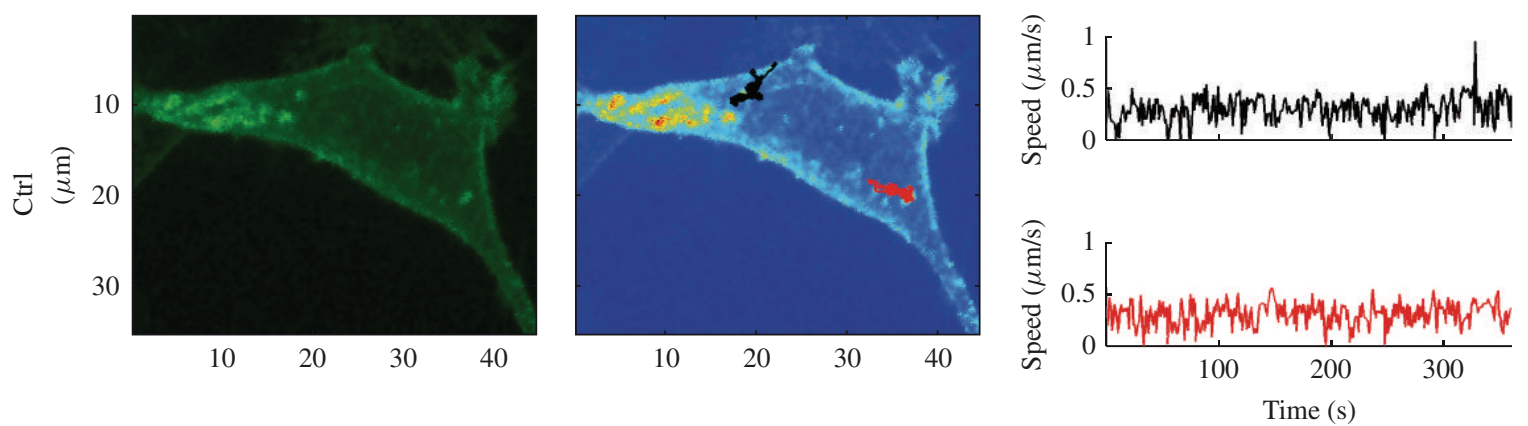

(a)

(b)

(c)

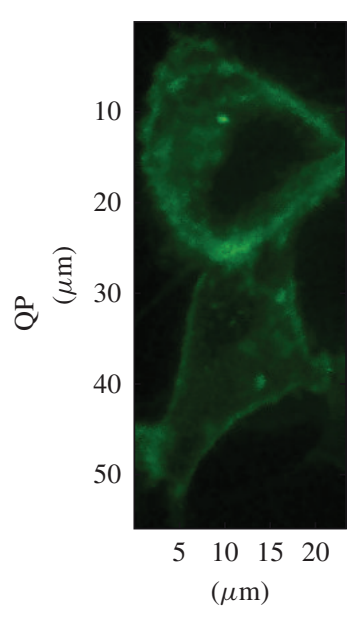

(d)

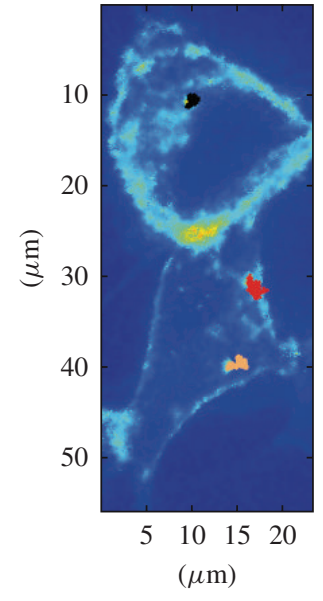

(e)

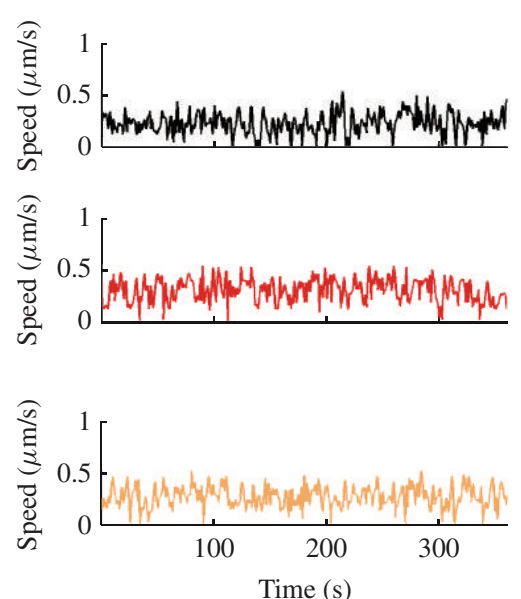

(f)

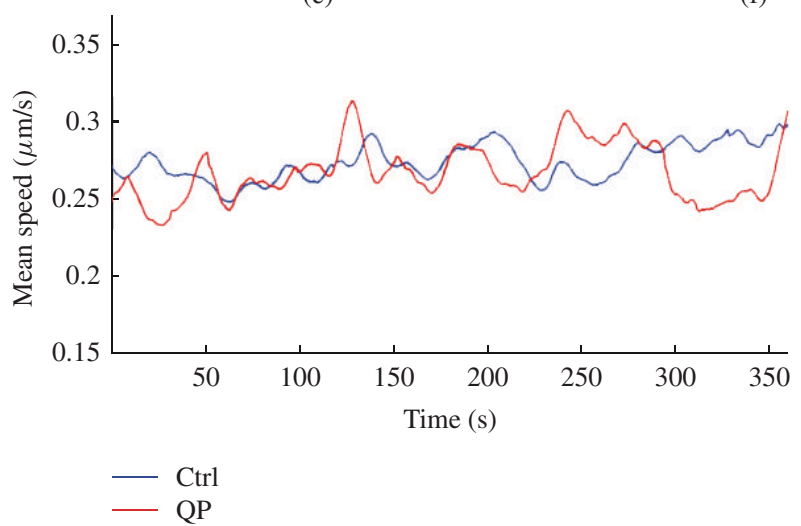

(g)

FIGURE 5: $D_{2 L} R$ vesicle trafficking. $D_{2 L} R$-YFP expressing cells were recorded for 6 min. Quinpirole (100 $\left.\mathrm{nM}\right)$ was added $30 \mathrm{~s}$ after the beginning of the experiment. A stack comprising the central part of the cells was used for analysis ( $a$ and $d$ ). Vesicle position was marked on the first frame of the stack to track it over time (b and e). Spatial deconvolution allowed to calculate the distance covered by the vesicles in medium- (c) and quinpirole-treated ( $f$ ) cells. Analysis of the mean distance covered by all analyzed vesicles (medium $n=23$, quinpirole $n=17$ ) indicated similar behavior in untreated and in agonist-treated cells.

When the vesicles containing $\mathrm{D}_{2 \mathrm{~L}} \mathrm{R}$-YFP were characterized, they clearly colocalized with the Golgi marker GM-130 and the endosomal marker transferrin receptor but not with the lysosomal marker LAMP-1. These associations were not altered in the presence of quinpirole (Figure 6(a)). The distribution 


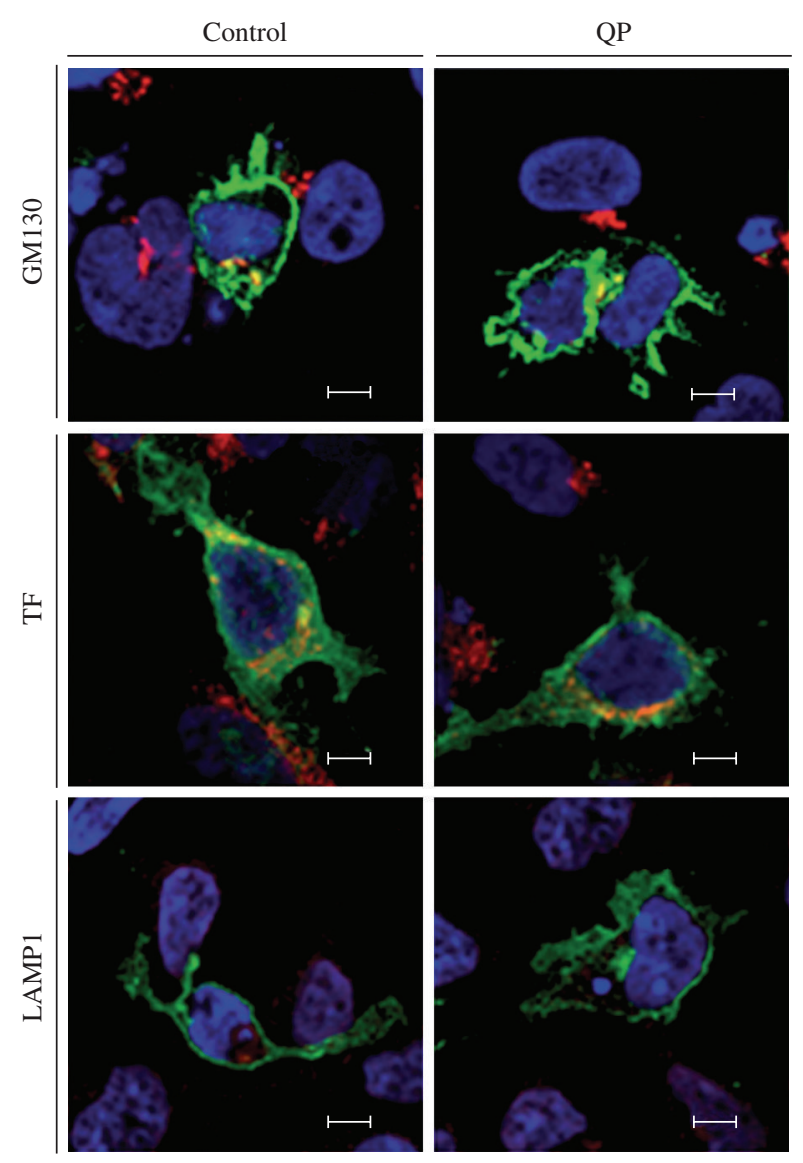

(a)
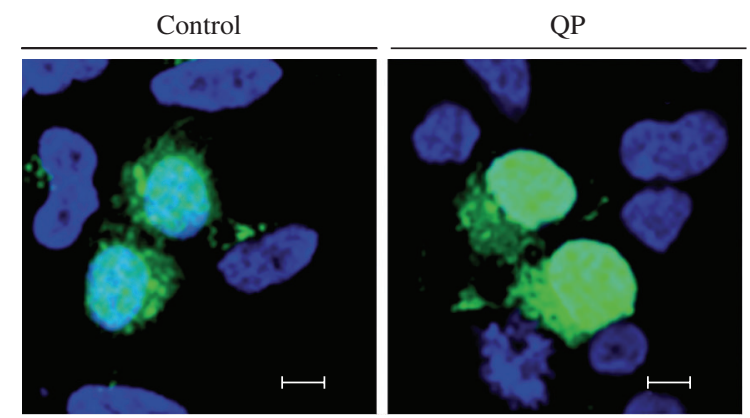

(b)

FIGURE 6: $D_{2 L} R$-YFP containing vesicle characterization. HEK-293T cells expressing $D_{2 L} R-Y F P$ (a) or YFP (b) were treated for 6 min with $100 \mathrm{nM}$ quinpirole. In (a) $D_{2 L} R$-YFP was detected by monitoring its own fluorescence (green) and, top to bottom, two representative images from different preparations showing (red) of GM130 (Golgi marker), of transferring receptor (endosomal marker), and of LAMP1 (lysosomal marker) are given. Cell nuclei were stained with Hoescht (blue). In (b) nuclear subcellular distribution of YFP (green) is shown in two representative images from different preparations. Scale bar: $10 \mu \mathrm{m}$.

of fluorescence was very different in cells transfected with YFP alone, which was mainly found in the cell nucleus and was not redistributed in the presence of quinpirole (Figure 6(b)). These results suggest that in the fusion protein, $D_{2 L} R$ is responsible for the specific localization of the $D_{2 L} R$-YFP-derived fluorescent signal and that short-term quinpirole treatment does not affect the colocalization of $\mathrm{D}_{2 \mathrm{~L}} \mathrm{R}-\mathrm{YFP}$ to vesicles containing the markers assayed. 


\section{3. $D_{2 L} R$ Internalization}

One of the early events that follow agonist binding is the rearrangement of the receptor along the cell surface. To study later events such as internalization, we analyzed the intensity of $\mathrm{D}_{2 L} \mathrm{R}-\mathrm{YFP}$ fluorescence at the cell surface in more long experiments. Fluorescence intensity was measured along a line of pixels that crossed the cell (Figures 7(a), 7(d), and 7(g)) in 360 images that were acquired over $3 \mathrm{~h}$ interval (i.e., one image every $30 \mathrm{~s}$ ). The photobleaching in these long-term low-exposure experiments was negligible, hence, the maximum fluorescence intensity at the two edges of the cell and the minimum fluorescence intensity (see Section 2.7.2) were computed for further analysis (Figures 7(b), 7(e), and 7(h)). The ratio between the maximum intensity on each side of the cell and the minimum fluorescence intensity was plotted (Figures 7(c), 7(f), and 7(i)) providing a measure of the degree of fluorescence loss from the cell surface. Accordingly, this parameter could serve as a real-time measure of internalization. $\mathrm{D}_{2 \mathrm{~L}} \mathrm{R}-$ YFP translocation from the plasma membrane was negligible in vehicle-treated cells (Figures 7(c) and 7(j)) and interestingly, similar results were obtained following exposure to quinpirole (Figures 7(f) and $7(\mathrm{j})$ ), indicating that no significant internalization of $\mathrm{D}_{2 \mathrm{~L}} \mathrm{R}-\mathrm{YFP}$ occurred even after triggering with high concentrations of this agonist. To test whether the lack of internalization of $\mathrm{D}_{2 \mathrm{~L}} \mathrm{R}-\mathrm{YFP}$ in HEK-293 cells was specific to this synthetic agonist, the effects of dopamine administration were also assayed. After a $3 \mathrm{~h}$ exposure, no significant differences in receptor localization were detected between cells treated with quinpirole (Figure 8(a)) or dopamine (Figure 8(b)).

$\mathrm{D}_{2 \mathrm{~L}} \mathrm{R}$ internalization requires phosphorylation by G-protein-coupled receptor kinases 2 or 5 (GRK2 or GRK5), and because HEK-293 cells express relatively low levels of these kinases, overexpression of these kinases may be necessary to trigger significant agonist-mediated receptor internalization [13, 14]. Therefore, we coexpressed $\mathrm{D}_{2 \mathrm{~L}} \mathrm{R}$-YFP and GRK2 in cells that were then recorded every $30 \mathrm{~s}$ for 3 hours in the presence or absence of quinpirole. Repeated measures one-way ANOVA revealed significant differences in the internalization index, and post-hoc tests showed that quinpirole provoked significantly greater internalization in cells cotransfected with GRK2 than in cells transfected with $\mathrm{D}_{2 \mathrm{~L}} \mathrm{R}$-YFP alone or in control cells exposed to the vehicle. Interestingly, significant differences were not observed until $97 \mathrm{~min}$ posttreatment although they were maintained until the end of the experiment $(180 \mathrm{~min})$. The results indicate that $\mathrm{D}_{2 \mathrm{~L}} \mathrm{R}$-YFP internalization in HEK-293 cells requires GRKs and that it occurs some time after agonist administration.

\section{DISCUSSION}

The study of dynamic processes in living cells requires high-speed data acquisition and the maintenance of an almost-constant cellular environment. Spinning disk confocal microscopy systems permit images to be obtained, significantly reducing the photobleaching induced by other approaches. Viability remains high during the time course of the experiment as the cells under observation are kept at a constant temperature and in a humid chamber with a $5 \% \mathrm{CO}_{2}$ atmosphere. By employing this technique to the study of $\mathrm{D}_{2 \mathrm{~L}} \mathrm{R}$ dynamics, we have been able to calculate parameters that are useful to analyze cell surface receptor dynamics.

As spinning disk microscopes cannot completely eliminate photobleaching, the first aim of this study was to characterize and correct for the photobleaching that occurs. Having corrected the images for this parameter, it was possible to determine the rate of lateral movement of a GPCR induced by agonist activation. Quinpirole administration led to an increase in the mobile receptor fraction, which may be due to higher fluidity of the bilayer structure and/or it may be assisted by scaffolding proteins. However, the rate of lateral movement $(0.08 \mu \mathrm{m} / \mathrm{s})$ was similar in the presence and absence of quinpirole, and it corresponded, to a distance covered each second that is equivalent to 20 -fold the diameter of the $\mathrm{D}_{2 \mathrm{~L}} \mathrm{R}$ (roughly $4 \mathrm{~nm}$ ). It has been suggested that hot spots, corresponding to accumulations of cell surface dopamine receptors, underlie the formation of endocytic vesicles in transfected $\mathrm{CHO}$ cells $[15,16]$. Our results indicate that in HEK-293 cells, the accumulation of $\mathrm{D}_{2 \mathrm{~L}} \mathrm{R}$ in specific areas of the plasma membrane does not necessarily 


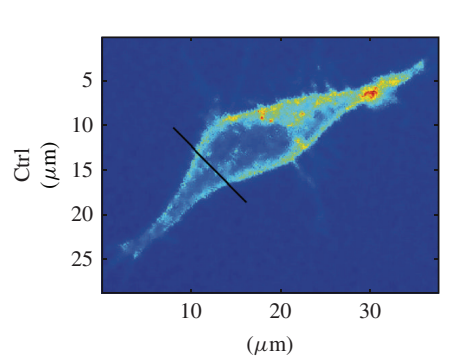

(a)

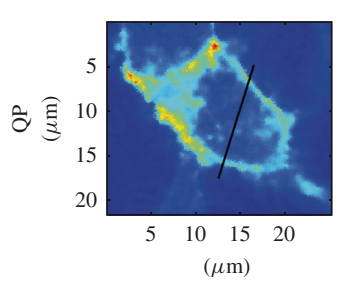

(d)

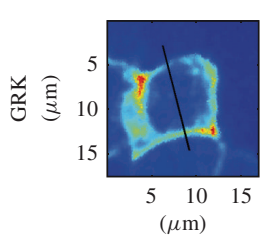

$(\mathrm{g})$

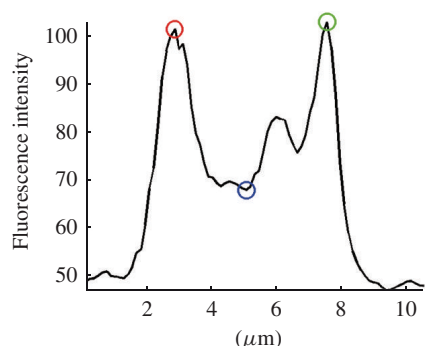

(b)

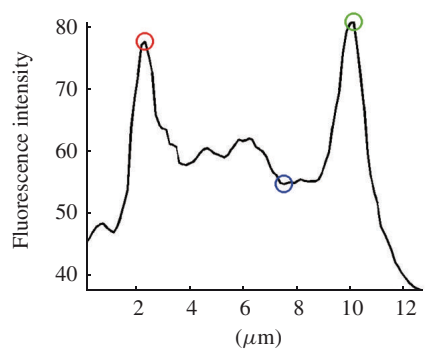

(e)

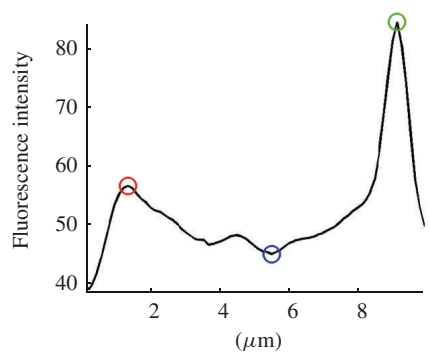

(h)

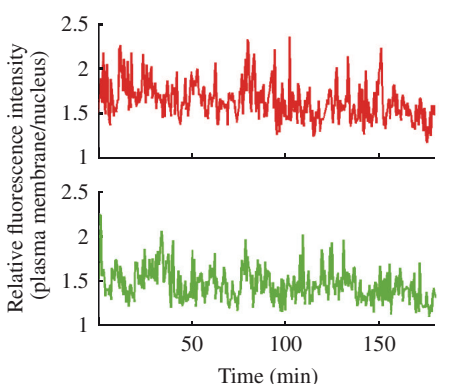

(c)

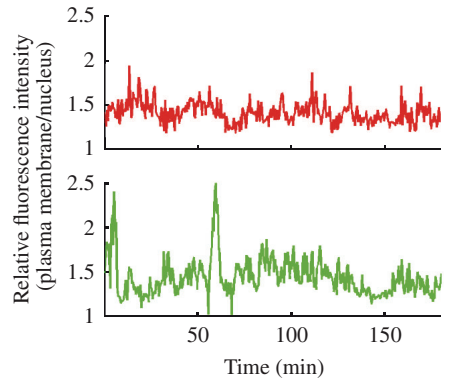

(f)

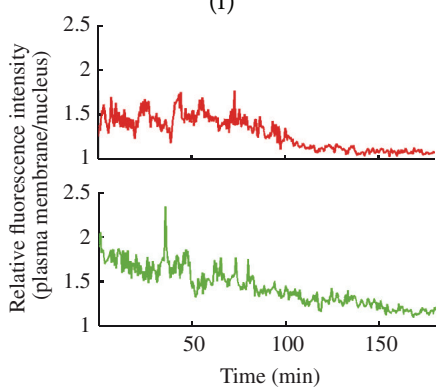

(i)

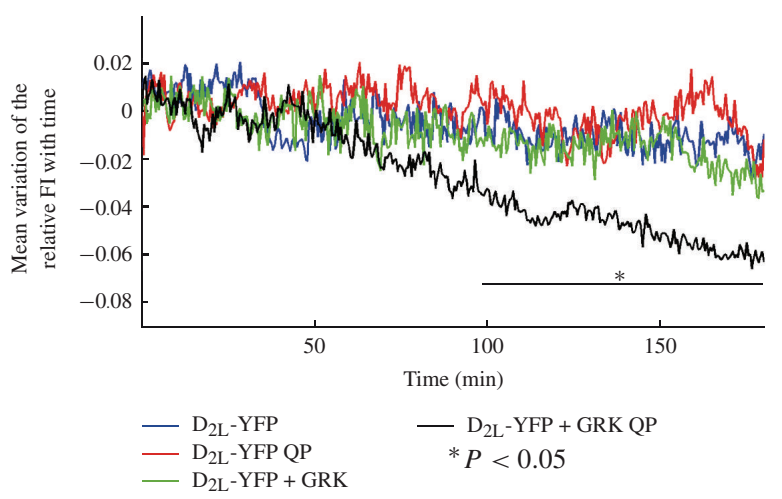

(j)

FIGURE 7: Study of $D_{2 L} R$ internalization. Receptor internalization was studied for 180 min on HEK-293 cells expressing $D_{2 L} R-Y F P$ or with $D_{2 L}$ R-YFP and GRK2. A stack comprising the central part of the cells was used for analysis. Fluorescence intensity was measured across a line crossing the cell in (a), (d), and (g) and was computed and plotted in, respectively (b), (e), and (h). For every plot the minimum of fluorescence intensity (blue circle) and the two maxima at both sides of the minimum (red and green circles) were detected. A ratio was established between the two maxima and the minimum, and the ratio evolution over time was plotted for each cell (c, f, and i). Normalized ratio of all analyzed cells is represented in (j). Using this approach, it was possible to detect statistical significant differences (One-way ANOVA) between $100 \mathrm{nM}$ quinpirole-treated cells expressing $D_{2 L}$ R-YFP and GRK2 and untreated or quinpirole-treated cells 97 minutes after treatment addition. In the absence of GRK2 coexpression there is not any detectable $D_{2 L} R$-YFP internalization. 
QP

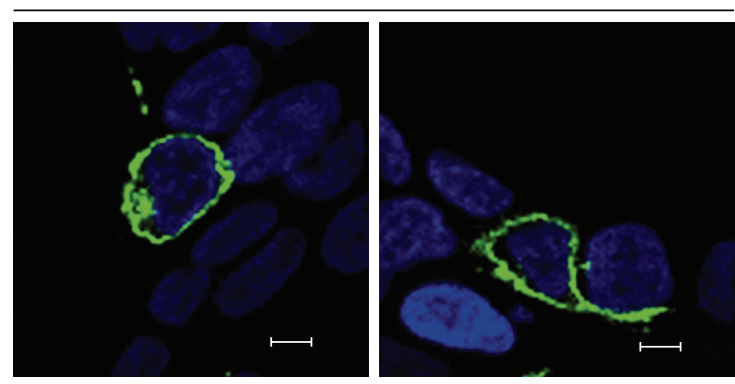

(a)

Dopamine

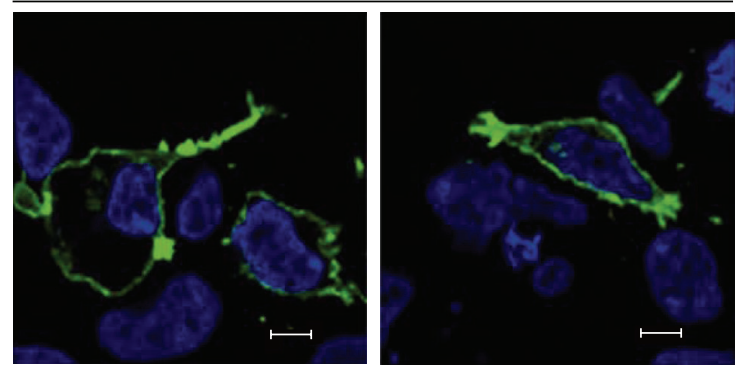

(b)

FIGURE 8: Effect of agonist treatment on $D_{2 L} R$ membrane expression. HEK-293T cells expressing $D_{2 L} R-$ YFP were treated for $180 \mathrm{~min}$ with $100 \mathrm{nM}$ quinpirole (a) or $50 \mathrm{nM}$ dopamine (b). $\mathrm{D}_{2 \mathrm{~L}} \mathrm{R}$-YFP was detected by monitoring its own fluorescence (green). Cell nuclei were stained with Hoescht (blue). For each condition two representative images from different preparations are shown. Scale bar: $10 \mu \mathrm{m}$.

trigger internalization, that is, that hot spots occur even in the absence of measurable agonist-driven receptor internalization.

In native tissues and cotransfected cells, $\mathrm{D}_{2} \mathrm{R}$ can form heteromers with other GPCRs such as the $\mathrm{A}_{2 \mathrm{~A}}$ adenosine receptor [17]. These heteromers have been detected in heterologous living cells using biophysical techniques, such as bioluminescence or fluorescence energy transfer [18-20]. The spinning disk confocal microscope used here enabled $\mathrm{D}_{2 \mathrm{~L}} \mathrm{R}$ movement to be rapidly monitored in real time. However, as the pixel size was $0.13 \mu \mathrm{m}$, this system could not be used to identify individual receptors. The fluorescence intensity detected in a single pixel depends on the number of receptors present in the area covered by the pixel. Therefore, the rate of movement corresponds to that of several receptor molecules. The degree of oligomerization detected by BRET (the so-called BRET signal) is not altered by agonist treatment [9] and hence the increase in the mobile fraction of $\mathrm{D}_{2 \mathrm{~L}} \mathrm{R}$ induced by quinpirole is, therefore, unlikely to result from the formation of higher-order structures. Taken together, these data suggest that receptor complexes do move but without altering the degree of receptor oligomerization. It should be stressed, however, that bioluminescence energy resonance techniques and/or the conditions of the energy transfer assays may not be suitable to measure changes in the degree of GPCR oligomerization.

A controversial hypothesis was proposed previously regarding the desensitization of the $\mathrm{D}_{2} \mathrm{R}-$ inhibited adenylyl cyclase system, and the up- or downregulation of cell surface $\mathrm{D}_{2} \mathrm{R}$ binding sites [21, 22]. However, this hypothesis is contradicted by the exquisite sensitivity of $\mathrm{D}_{2} \mathrm{R}$ agonists that was demonstrated in long-term human therapies, such as that required to combat prolactin-secreting adenomas [23]. Our data show that the long isoform of the $\mathrm{D}_{2}$ receptor exhibits little agonist-induced downregulation. Indeed, the colocalization of $\mathrm{D}_{2 \mathrm{~L}} \mathrm{R}$ in vesicles with Golgi and endosomal but not with lysosomal markers also indicates that their efficacy is preserved. These data are consistent with findings showing that resistance of 
the $\mathrm{D}_{2 \mathrm{~L}} \mathrm{R}$ receptor-coupled adenylyl cyclase system to agonist-induced desensitization may be due to an increase in cell surface receptors through the translocation of existing intracellular receptors and de novo receptor synthesis [22]. The reported down-regulation of $\mathrm{D}_{2} \mathrm{R}$ [21] may only apply to the short isoform, the binding sites of which disappear faster from the cell surface than those of the long isoform [24], or to differences in the cell model or technical approaches used. Our findings suggest that down-regulation of the $\mathrm{D}_{2 \mathrm{~L}} \mathrm{R}$ occurs faster in cell lines expressing higher levels of GRK. Indeed, coexpression of $\mathrm{D}_{2 \mathrm{~L}} \mathrm{R}$ and GRK2 in HEK-293 cells produced significant $\mathrm{D}_{2 \mathrm{~L}} \mathrm{R}$ internalization. We cannot rule out the possibility that the presence of YFP affects the degree and time-course of receptor down-regulation; moreover, the assay of agonist activation in the presence of anti- $\mathrm{D}_{2} \mathrm{R}$ antibodies may also affect receptor trafficking. However, to the best of our knowledge the imaging of living HEK-293 cells expressing the fluorescenttagged receptor is a convenient and reliable approach to study default trafficking of $\mathrm{D}_{2 \mathrm{~L}} \mathrm{R}$. Furthermore, the image-based approach described here can reveal cell surface microdomains that may be hidden when using other techniques.

In summary, the method of image analysis described here represents a novel and valuable tool for the qualitative and quantitative evaluation of GPCR dynamics. Using this approach, it is possible to detect events, such as the lateral movement of $\mathrm{D}_{2 \mathrm{~L}} \mathrm{R}$ even in the absence of agonist triggering the slow disappearance of agonist-activated $\mathrm{D}_{2 \mathrm{~L}} \mathrm{R}$ from the plasma membrane and its acceleration upon GRK2 coexpression.

\section{ACKNOWLEDGMENTS}

The authors thank Dr. Carlos Ortiz de Solórzano (Image Unit, CIMA) for advise and acknowledge Carmen Molina for helpful technical support. This work was supported by the UTE-project/Foundation for Applied Medical Research (F.I.M.A.) and by Grants SAF2008-03229-E/and SAF2009-07276 from Spanish Ministerio de Ciencia y Tecnología.

\section{REFERENCES}

[1] E. Wang, C. M. Babbey, and K. W. Dunn, "Performance comparison between the high-speed Yokogawa spinning disc confocal system and single-point scanning confocal systems," Journal of Microscopy, vol. 218, no. 2, pp. $148-159,2005$.

[2] S. Inoué and T. Inoué, "Direct-view high-speed confocal scanner: the CSU-10," Methods in Cell Biology, vol. 2002, no. 70, pp. 87-127, 2002.

[3] M. El-Ghundi, B. F. O'Dowd, and S. R. George, "Insights into the role of dopamine receptor systems in learning and memory," Reviews in the Neurosciences, vol. 18, no. 1, pp. 37-66, 2007.

[4] P. A. LeWitt, "Levodopa for the treatment of Parkinson's disease," New England Journal of Medicine, vol. 359, no. 23, pp. 2468-2476, 2008.

[5] J. A. Lieberman, F. P. Bymaster, H. Y. Meltzer et al., "Antipsychotic drugs: comparison in animal models of efficacy, neurotransmitter regulation, and neuroprotection," Pharmacological Reviews, vol. 60, no. 3, pp. 358403, 2008.

[6] A. Dumoulin, A. Triller, and M. Kneussel, "Cellular transport and membrane dynamics of the glycine receptor," Frontiers in Molecular Neuroscience, vol. 2, p. 28, 2009.

[7] J. W. Dobrucki, D. Feret, and A. Noatynska, "Scattering of exciting light by live cells in fluorescence confocal imaging: phototoxic effects and relevance for FRAP studies," Biophysical Journal, vol. 93, no. 5, pp. 1778-1786, 2007.

[8] P. S. Maddox, B. Moree, J. C. Canman, and E. D. Salmon, "Spinning disk confocal microscope system for rapid high-resolution, multimode, fluorescence speckle microscopy and green fluorescent protein imaging in living cells," Methods in Enzymology, vol. 360, pp. 597-617, 2003.

[9] M. Canals, D. Marcellino, F. Fanelli et al., "Adenosine $\mathrm{A}_{2 A}$-dopamine $\mathrm{D}_{2}$ receptor-receptor heteromerization: qualitative and quantitative assessment by fluorescence and bioluminescence energy transfer," Journal of Biological Chemistry, vol. 278, no. 47, pp. 46741-46749, 2003. 
[10] P. Penela, A. Elorza, S. Sarnago, and F. Mayor Jr, " $\beta$-arrestin- and c-Src-dependent degradation of G-proteincoupled receptor kinase 2," EMBO Journal, vol. 20, no. 18, pp. 5129-5138, 2001.

[11] G. Navarro, S. Ferre, A. Cordomi et al., "Interactions between intracellular domains as key determinants of the quaternary structure and function of receptor heteromers," Journal of Biological Chemistry, vol. 285, no. 35, pp. 27346-27359, 2010.

[12] E. Moreno, S. H. Vaz, N. S. Cai et al., "Dopamine-galanin receptor heteromers modulate cholinergic neurotransmission in the rat ventral hippocampus," Journal of Neuroscience, vol. 31, no. 20, pp. 7412-7423, 2011.

[13] K. Ito, T. Haga, J. Lameh, and W. Sadée, "Sequestration of dopamine $\mathrm{D}_{2}$ receptors depends on coexpression of G-protein-coupled receptor kinases 2 or 5," European Journal of Biochemistry, vol. 260, no. 1, pp. 112-119, 1999.

[14] K. M. Kim, K. J. Valenzano, S. R. Robinson, W. D. Yao, L. S. Barak, and M. G. Caron, "Differential regulation of the dopamine $\mathrm{D}_{2}$ and $\mathrm{D}_{3}$ receptors by $\mathrm{G}$ protein-coupled receptor kinases and $\beta$-arrestins," Journal of Biological Chemistry, vol. 276, no. 40, pp. 37409-37414, 2001.

[15] S. Genedani, D. Guidolin, G. Leo et al., "Computer-assisted image analysis of caveolin-1 involvement in the internalization process of adenosine $\mathrm{A}_{2 A}$-dopamine $\mathrm{D}_{2}$ receptor heterodimers," Journal of Molecular Neuroscience, vol. 26, no. 2-3, pp. 177-184, 2005.

[16] M. Torvinen, C. Torri, A. Tombesi et al., "Trafficking of adenosine $\mathrm{A}_{2 A}$ and dopamine $\mathrm{D}_{2}$ receptors," Journal of Molecular Neuroscience, vol. 25, no. 2, pp. 191-200, 2005.

[17] J. Hillion, M. Canals, M. Torvinen et al., "Coaggregation, cointernalization, and codesensitization of adenosine $\mathrm{A}_{2 A}$ receptors and dopamine $\mathrm{D}_{2}$ receptors," Journal of Biological Chemistry, vol. 277, no. 20, pp. 18091-18097, 2002.

[18] G. Navarro, P. Carriba, J. Gandia et al., "Detection of heteromers formed by cannabinoid CB1, dopamine $\mathrm{D}_{2}$, and adenosine $\mathrm{A}_{2 A}$ G-protein-coupled receptors by combining bimolecular fluorescence complementation and bioluminescence energy transfer," TheScientificWorldJOURNAL, vol. 8, pp. 1088-1097, 2008.

[19] P. Carriba, G. Navarro, F. Ciruela et al., "Detection of heteromerization of more than two proteins by sequential BRET-FRET," Nature Methods, vol. 5, no. 8, pp. 727-733, 2008.

[20] N. Cabello, J. Gandia, D. C.G. Bertarelli et al., "Metabotropic glutamate type 5, dopamine $\mathrm{D}_{2}$ and adenosine $\mathrm{A}_{2 a}$ receptors form higher-order oligomers in living cells," Journal of Neurochemistry, vol. 109, no. 5, pp. 1497-1507, 2009.

[21] S. E. Bartlett, J. Enquist, F. W. Hopf et al., "Dopamine responsiveness is regulated by targeted sorting of $\mathrm{D}_{2}$ receptors," Proceedings of the National Academy of Sciences of the United States of America, vol. 102, no. 32, pp. 11521-11526, 2005.

[22] G. Y. Ng, G. Varghese, H. T. Chung et al., "Resistance of the dopamine $\mathrm{D}_{2 L}$ receptor to desensitization accompanies the up-regulation of receptors on to the surface of Sf9 cells," Endocrinology, vol. 138, no. 10, pp. 41994206, 1997.

[23] G. Y. Ng and S. R. George, "Pituitary adenomas," Contemporary Oncology, pp. 4-10, 1992.

[24] M. Itokawa, M. Toru, K. Ito et al., "Sequestration of the short and long isoforms of dopamine $\mathrm{D}_{2}$ receptors expressed in Chinese hamster ovary cells," Molecular Pharmacology, vol. 49, no. 3, pp. 560-566, 1996.

\section{This article should be cited as follows:}

María S. Aymerich, J. López-Azcárate, J. Bonaventura, G. Navarro, D. Fernández-Suárez, V. Casadó, F. Mayor, C. Lluís, M. Valencia, J. Artieda, and Rafael Franco, "Real-Time G-Protein-Coupled Receptor Imaging to Understand and Quantify Receptor Dynamics," TheScientificWorldJOURNAL, vol. 11, pp. 1995-2010, 2011. 

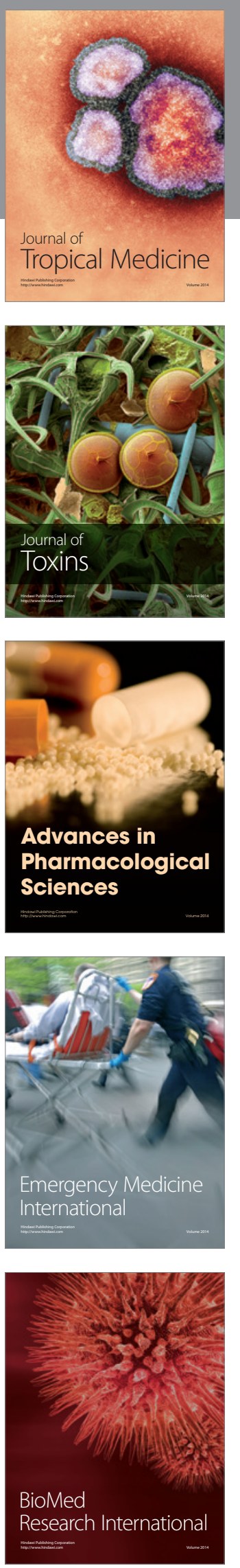
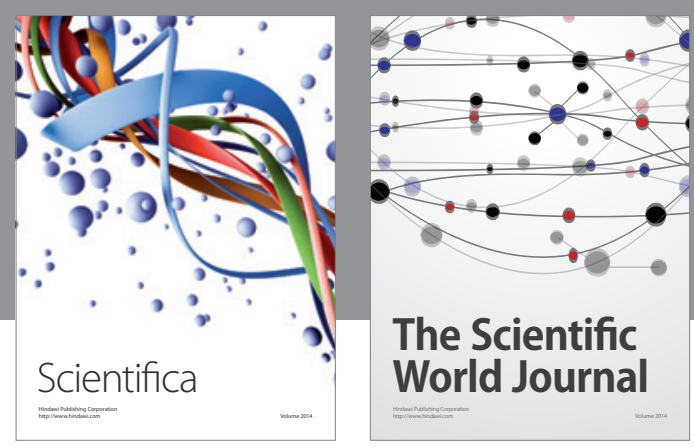

The Scientific World Journal
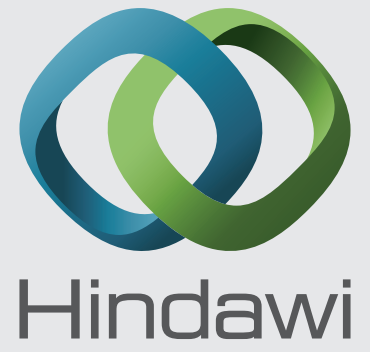

Submit your manuscripts at

http://www.hindawi.com
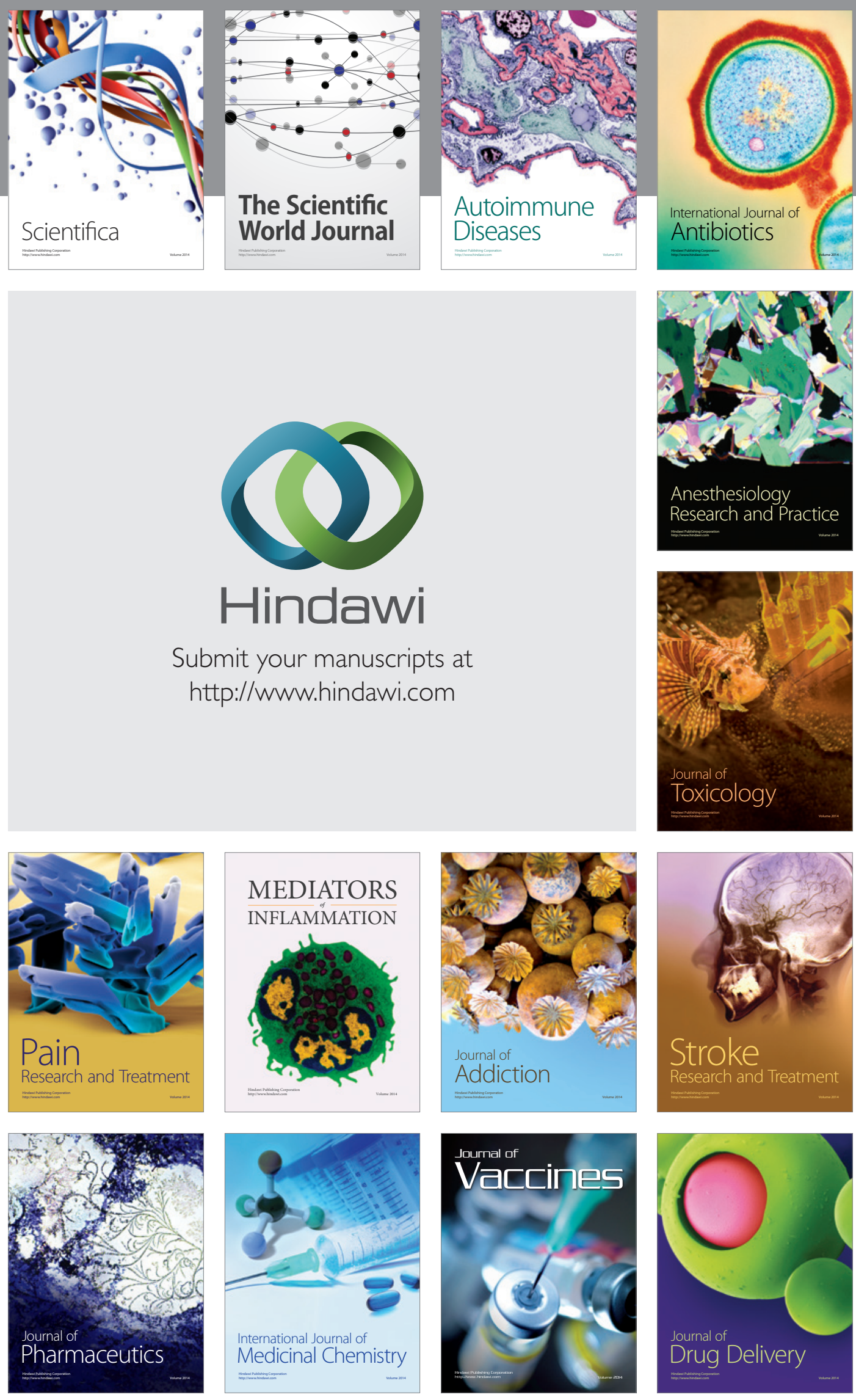